\title{
Perceptions of the causes of schizophrenia and associated factors by the Holy Trinity Theological College students in Ethiopia
}

\author{
Melat Solomon ${ }^{2 *}$, Telake Azale ${ }^{1}$, Awake Meherte ${ }^{2}$, Getachew Asfaw² and Getinet Ayano²
}

\begin{abstract}
Introduction: There is a cultural variability around the perception of what causes the syndrome of schizophrenia. As far as the cause of schizophrenia by the general public concerned, people living in western countries focus mainly on biological and social risk factors such as genetic vulnerability, disease of the brain, infection or stressful social conditions or personal weakness, but the predominant views held by people living in non-western countries focus mainly on supernatural and religious factors. Awareness and beliefs about the causes of mental illnesses influence the preferred treatments. The aim of this study was to determine the perceptions regarding the etiology of schizophrenia and the associated factors by theology students.
\end{abstract}

Methods: An institution-based cross-sectional study was conducted among Holy Trinity Theological College students from May to June 2016. Self-administered Short Explanatory Model Interview was used to assess the perception of what causes the syndrome of schizophrenia. Data entry was performed by Epi-info version 3.5.3 and the Statistical Program for Social Science (SPSS version 20) was used for data clearance, and analyses.

Results: A total of 409 students were involved in the survey. The mean age of the participants was 33.3 years (standard deviation \pm 8.3 ) and almost all $94.4 \%$ of them were males. The majority (81.7\%) of the participant recognized schizophrenia as a mental illness. Only $16.9 \%$ of the participants attributed supernatural phenomenon as a cause of schizophrenia and most of them $76.5 \%$ (313) thought of psychosocial problems as the cause of schizophrenia. About $40.1 \%$ of the participant endorsed biological factors as a cause of schizophrenia. About two-thirds (68.2\%) of the participant thought schizophrenia as severe but not fatal illness and about $22.2 \%$ of them thought both severe and fatal illness. As far as the course concerned majority (88.5\%) of the participants thought schizophrenia as a chronic illness and about 11.5\% thought acute illness. Regarding the treatment, almost all (99.8\%) of reported schizophrenia is treatable. Moreover, concerning the consequences of the illness about $18.8 \%$ reported the death as a consequence and about 66.7, 34.7 and $7.8 \%$ reported madness, family disintegration and losing a job, respectively. Urban residency and holding other degree were significantly associated with biological factors as a cause of schizophrenia $(p<0.05)$. Whereas getting information from mass media and health professional, marital status (married) and urban residence were significantly associated with psychosocial factors as the cause of schizophrenia. Furthermore, rural residency was significantly associated with the supernatural phenomenon as the cause of schizophrenia.

Conclusion: In the current study, the majority of the participant recognized schizophrenia as a mental illness and a treatable syndrome. A vast majority of the participant thought of psychosocial problems as the cause of schizophrenia about two-thirds of the participant thought schizophrenia as a severe but not fatal illness. As far as the course concerned majority (88.5\%) of the participants thought schizophrenia as a chronic illness. Concerning the consequences of

\footnotetext{
*Correspondence: mimisolomon2010@gmail.com

${ }^{2}$ Research and Training Department, Amanuel Mental Specialized

Hospital, Addis Ababa, Ethiopia

Full list of author information is available at the end of the article
}

(c) The Author(s) 2018. This article is distributed under the terms of the Creative Commons Attribution 4.0 International License (http://creativecommons.org/licenses/by/4.0/), which permits unrestricted use, distribution, and reproduction in any medium, provided you give appropriate credit to the original author(s) and the source, provide a link to the Creative Commons license, and indicate if changes were made. The Creative Commons Public Domain Dedication waiver (http://creativecommons.org/ publicdomain/zero/1.0/) applies to the data made available in this article, unless otherwise stated. 
the illness, about $18.8 \%$ reported the death as a consequence and about $66.7,34.7$, and $7.8 \%$ reported madness, family disintegration and losing a job, respectively. Residency, marital status, and source of information were significantly associated with perceived causes of schizophrenia. Linking mental health service with spiritual care to address community mental health care needs and for early detection as well as referral linkage of mentally ill patients is warranted.

\section{Background}

Schizophrenia is defined as a clinical syndrome of the variable, but deeply disruptive, psychopathology that involves cognition, emotion, perception, and other aspects of behavior. The hallmark symptom of schizophrenia is psychosis, such as experiencing auditory hallucinations (voices) and delusions (fixed false beliefs) [1] Schizophrenia is the most severe among common severe psychiatric disorders. It is among the most disabling and economically catastrophic medical disorders, ranked by the World Health Organization as one of the top ten illnesses contributing to the global burden of disease [2]. There are numerous factors that contribute to the risk of developing schizophrenia. In general, it is a disease caused by a combination of bio-psychosocial influences including genetic, perinatal, and neuroanatomical, neurochemical and other biologic abnormalities [3, 4].

As far as the cause of schizophrenia by the general public concerned, people living in western countries focus mainly on biological and social risk factors such as genetic vulnerability, disease of the brain, infection or stressful social conditions or personal weakness [5-8], but the predominant views held by people living in non-western countries focus mainly on supernatural and religious fact [9-12]. Studies from Australia, Ireland, Germany, Switzerland, UK, and USA have found that social factors were most often seen as the causes of schizophrenia [9-13], whereas genetic factors were much less frequently endorsed [9-11, 13]. Social factors are also seen by the public of Western countries as an important cause of schizophrenia [7, 10, 13, 14]. While genetic factors are more often seen as a cause for schizophrenia than depression, they are still endorsed much less frequently than social factors $[9,13]$. In Ethiopia, there is a widespread belief that severe mental illnesses are due to demon possession, bewitchment by an evil spirit and evil eye which existed for many years due to lack of awareness about mental illness [15].

Of greater concern is the stigmatizing belief that mental disorders are caused by personal weakness or a punishment from God. Awareness and beliefs about the causes of mental illnesses influence the preferred treatments [16, 17]. People living in non-western countries mainly rely on indigenous healing practices which are defined as thelping beliefs and strategies that originate within a culture or society and that are designed for treating the members of a given cultural group [18]. A research done in Nigeria showed that the majority of people preferred indigenous over the modern health care system which was consistent with their predominant belief about causes of mental illnesses [19]. A study in Ethiopia also showed a preference for indigenous practices for mental disorders and modern medicine is more preferred for somatic conditions [20].

The gap between the need for treatment of mental disorder and its provision is wide all over the world. For example between 76 and $85 \%$ of people with severe mental illnesses receive no treatment for their mental health problem [6]. To address the mental health service gaps, integrated management of mental disorders at primary health care level as well as working with traditional healers and spiritual organizations is recommended especially in low- and middle-income countries including Ethiopia. However, there is a gap with respect to collaboration with the faith and traditional healers to create awareness and promote modern mental health care [21].

While there has been considerable research on public beliefs, there has been little research concerning the belief of religious leaders including theology students. Therefore, in view of the above issues, the aim of this study was: (1) to explore the perceived causes of schizophrenia by theology students; (2) to identify the factors associated with perceived causes of schizophrenia.

\section{Methods \\ Study setting and design}

Institutional-based cross-sectional study was conducted at Holy Trinity Theological College, May 2016, Addis Ababa, Ethiopia. Holy Trinity Theological College (HTTC) is a theological school of higher education located in Addis Ababa, Ethiopia. The college provides religious and secular instruction to both clergies and lay members of the Ethiopian Orthodox Church. In addition, the institution serves as a center of theological and ecclesiastical study for all Oriental Orthodox Churches. The college gives both undergraduate and postgraduate training and the trained professionals are expected to work as spiritual teachers and also expected to involve in different managerial positions of the Ethiopian Orthodox church. The graduates of the Holy Trinity Theological College are the most expected peoples in Ethiopia because they are assumed to be a bridge between the people and God. The 
Ethiopian Church has a membership of between 40 and 46 million, the majority of whom live in Ethiopia, and is, thus, the largest of all Oriental Orthodox churches.

\section{Study population}

The study population consisted of all students who were attending Holy Trinity Theological College and included in the sample. Those who are unable to communicate due to different reasons were excluded from the study.

\section{Sampling procedures}

The sample size was calculated using Epi-info software version 3.5 .2 by considering the following assumptions: $95 \%$ Confidence Interval, $80 \%$ power, $50 \%$ proportion of etiology of schizophrenia, odds ratio to be detected 2, Non-response rate $10 \%$. The final sample size was 423 . Simple random sampling technique was used to select the study participants.

\section{Data collection}

The data were collected by semi-structured, self-administered Short Explanatory Model Interview (SEMI) version 3.2 It is developed by Lloyd et al. [22] and modified by different psychiatrists to Ethiopian version to measure perception with modification to make it suitable for nonpatients that were respond based on case vignettes. The questionnaires were including socio-demographic characteristics, clinical factors, and source of information. Questionnaires were asked after reading the vignette case. As recommended by WHO a case vignette study has also been used in a study in Ethiopia to evaluate mental health training and its implication for integrated mental health services [23], a study Butajira to assess attitude about mental disorders [20], on Ethiopian medical students [24], and as part of the national mental health plan in the United Republic of Tanzania [25], and to assess perception and attitude of the community about mental disorders in Ethiopia [26].

\section{Data processing and analyses}

Data were analyzed using SPSS version 20. Frequency and percentage were used to describe the data. Bivariate analysis was done to see the association of each independent variable with the outcome variable. Those variables having a $p<0.2$ were entered into the multivariate logistic regression model to identify the effect of each independent variable with the outcome variables. A $p<0.05$ was considered statistically significant, and the adjusted odds ratio with $95 \%$ CI was calculated to determine the association.

\section{Ethical consideration}

Ethical clearance was obtained from the University of Gondar Ethical Review Board (ERB) and Amanueal
Mental Specialized Hospital Ethical Review Board. Informed consent was obtained from each participant during data collection. All participants were informed about the aim and purpose of the study. The right was given to the study participant to refuse and stop or withdraw from participation at any time during data collection without loss of any entitlement. For the purpose of anonymity, participants name was not used at the time of data collection and all other personnel information was kept entirely anonymous and confidential.

\section{Results}

Socio-economic and demographic characteristics

A total of 409 participants were included in the study which makes the response rate $96.7 \%$. The mean age of the respondents was $33.3(\mathrm{SD} \pm 8.3)$ and almost all $386(94.4 \%)$ were males. About $184(45.0 \%)$ of the participants were Amhara by ethnicity. More than half 223 (54.5\%) were single and 186 (45.5\%) married. About 215 (52.6\%) of participants were from urban, the remaining 194 (47.4) came from rural areas. Regarding previous college training of the participants, about 167 (40.8\%) respondents have held a diploma and other degrees; of these 83 (20.1\%) had training related to business and construction profession, about 51 (12.5\%) had training related to health, and $35(8.6 \%)$ were teachers. Moreover, about 159 (38.9\%) of the participants had a diploma-level training, 227 (55.5\%) had a degree-level training, and 23 (5.6\%) had master's degree (see Table 1).

\section{Clinical factors and source of information of respondents}

Among the total participants, 111 (22.1\%) of respondents were reported to have a family history of mental illness and about 13 (3.2\%) had a previous mental illness. Regarding the source about mental illness, all respondents reported as having mental illness-related information; from this, 322 (78.7) heard the information from social media (see Table 2).

\section{Perceived cause, course, outcomes and treatment of schizophrenia by participants}

The majority (81.7\%) of the participant recognized schizophrenia as a mental illness. Only $16.9 \%$ of the participants attributed supernatural phenomenon as a cause of schizophrenia and most of them 76.5\% (313) thought of psychosocial problems as the cause of schizophrenia. About $40.1 \%$ of the participant endorsed biological factors as a cause of schizophrenia. About two-thirds (68.2\%) of the participant thought schizophrenia as severe but not fatal illness, and about $22.2 \%$ of them thought both severe and fatal illness. 
Table 1 Frequency of socio-demographic characteristics of Holy Trinity Theological College students at Addis Ababa Ethiopia $2016(n=409)$

\begin{tabular}{|c|c|c|}
\hline Variable & Frequency & Percentage \\
\hline \multicolumn{3}{|l|}{ Age } \\
\hline Mean (SD) & $33.3(8.3)$ & \\
\hline \multicolumn{3}{|l|}{ Sex } \\
\hline Male & 386 & 94.4 \\
\hline Female & 23 & 5.5 \\
\hline \multicolumn{3}{|l|}{ Ethnicity } \\
\hline Amhara & 184 & 45.0 \\
\hline Tigre & 92 & 22.5 \\
\hline Oromo & 49 & 12.0 \\
\hline Gurage & 54 & 13.2 \\
\hline S.N.N.P & 30 & 7.3 \\
\hline \multicolumn{3}{|l|}{ Marital status } \\
\hline Single & 223 & 54.5 \\
\hline Marred & 186 & 46.1 \\
\hline \multicolumn{3}{|l|}{ Residency } \\
\hline Urban & 215 & 52.6 \\
\hline Rural & 194 & 47.4 \\
\hline \multicolumn{3}{|l|}{ Educational level } \\
\hline Diploma & 159 & 38.9 \\
\hline Degree & 227 & 55.5 \\
\hline Masters & 23 & 5.5 \\
\hline \multicolumn{3}{|l|}{ Background profession } \\
\hline Yes & 167 & 40.8 \\
\hline No & 242 & 59.1 \\
\hline \multicolumn{3}{|l|}{ Type of profession } \\
\hline Business and construction & 83 & 20.1 \\
\hline Health profession & 51 & 12.5 \\
\hline Teaching & 35 & 8.6 \\
\hline
\end{tabular}

Table 2 Frequencies of family history of mental illness, previous history of mental illness and sources of information among Holy Trinity Theological College students Addis Ababa Ethiopia 2016

\begin{tabular}{lll}
\hline Variable & Frequency & Percentage \\
\hline Family history of mental illness & & \\
No & 298 & 27.1 \\
Yes & 111 & 72.9 \\
Previous mental illness & & \\
No & 396 & 96.8 \\
Yes & 13 & 3.2 \\
Sources of information & & \\
Social media & 322 & 78.7 \\
Mass media & 241 & 58.9 \\
Health professional & 196 & 47.9 \\
\hline
\end{tabular}

As far as the course concerned, majority (88.5\%) of the participants thought schizophrenia as a chronic illness and about $11.5 \%$ thought acute illness. Regarding the treatment, almost all (99.8\%) of reported schizophrenia is treatable. Moreover, concerning the consequences of the illness, about $18.8 \%$ reported the death as a consequence and about $66.7,34.7$ and $7.8 \%$ reported madness, family disintegration and losing a job, respectively (see Table 3 ).

Table 3 Frequency of perceived cause of schizophrenia by Holy Trinity theological college students Addis Ababa 2016

\begin{tabular}{|c|c|c|}
\hline \multirow[t]{2}{*}{ Variable } & \multicolumn{2}{|c|}{ Schizophrenia } \\
\hline & Frequency & Percentage \\
\hline \multicolumn{3}{|l|}{ Name } \\
\hline Non specific psychi/psycho dx & 318 & 77.8 \\
\hline Unable to say & 55 & 13.4 \\
\hline Supernatural/spiritual & 18 & 4.4 \\
\hline Specific psychi/psycho dx & 16 & 3.9 \\
\hline Non specific physiology $d x$ & 1 & 0.2 \\
\hline Specific physiological dx & 1 & 0.2 \\
\hline \multicolumn{3}{|l|}{ Cause } \\
\hline Psychosocial & 313 & 76.3 \\
\hline Supernatural/spiritual & 90 & 16.9 \\
\hline Biological & 61 & 14.9 \\
\hline \multicolumn{3}{|l|}{ Severity } \\
\hline Severe but not fatal & 278 & 68.2 \\
\hline Severe and fatal & 91 & 22.2 \\
\hline Moderate & 32 & 7.8 \\
\hline Mild & 8 & 2.0 \\
\hline \multicolumn{3}{|l|}{ Course of illness } \\
\hline Chronic & 362 & 88.5 \\
\hline Acute & 46 & 11.2 \\
\hline Life long & 1 & 0.02 \\
\hline \multicolumn{3}{|l|}{ Treatment } \\
\hline Yes & 409 & 100. \\
\hline No & 0 & \\
\hline \multicolumn{3}{|l|}{ Treatment option } \\
\hline Psychosocial & 280 & 68.5 \\
\hline Spiritual/traditional & 194 & 47.4 \\
\hline Biological & 164 & 40.1 \\
\hline \multicolumn{3}{|l|}{ Treatment outcome } \\
\hline Treatable & 408 & 99.8 \\
\hline Not treatable & 1 & 0.2 \\
\hline \multicolumn{3}{|l|}{ Consequence } \\
\hline Madness & 278 & 66.7 \\
\hline Family disintegration & 142 & 34.7 \\
\hline Death & 77 & 18.8 \\
\hline Loosing job & 32 & 7.8 \\
\hline
\end{tabular}

DX diagnosis, Psycho psychological, Psychi psychiatric 
Factors associated with the perceived cause of schizophrenia among Holy Trinity Theological College students

During multivariable analysis, variables residency, having another profession, marital status and source of information were significantly associated with perceived causes of schizophrenia.

In our multivariate logistic regression, individuals who were from the urban area were strongly associated $[\mathrm{AOR}=3.34(1.63,6.80)]$ with perceived biological causation. Those having other background profession were strongly and positively associated with the perceived biological cause of schizophrenia with $[\mathrm{AOR}=5.17$ (2.67, 10.23)]. Residency (urban) was also positively associated with the perceived psychosocial cause of schizophrenia with $[\mathrm{AOR}=1.72(1.03,2.86)]$. Respondents those who are married were associated with the psychosocial cause of schizophrenia with $(\mathrm{AOR}=0.46(0.25,0.866)$. Getting information about mental illness from mass media $[\mathrm{AOR}=1.999(1.22,3.26)]$ and from a health professional $[\mathrm{AOR}=1.888(1.158,3.07)]$ were associated with the perceived psychosocial cause of schizophrenia. Perceived supernatural/spiritual cause of schizophrenia was strongly associated with those who came from rural residency with $[$ AOR $=3.107(1.8,5.314)]$ (See Table 4).

\section{Discussion}

To the best of our knowledge, this is the first study which examined the perceived cause of schizophrenia, and associated factors among Holy Trinity Theological College students. The study revealed that only $16.9 \%$ of the participants attributed supernatural phenomenon as a cause of schizophrenia and most of them 313 (76.5\%) reported psychosocial problems as the cause of schizophrenia. The findings of this study were different than the results from the previous studies in Nigeria which showed the perceived cause of schizophrenia to be supernatural in $93.8 \%$ [27] and study done in Ethiopia where most frequently mentioned cause of mental illness spirit possession $51.6 \%$ [28]. This could be the difference between study participants. Since they are theological college students and they had the basic academic background. The other possible cause could be due to more than half respondents are from urban dwelling; this might help them to better access to getting information. Another reason may be that the psychology course is included in their curriculum.

In the current study, majority $(81.7 \%)$ of the participant recognized schizophrenia as a mental illness. This could be due to almost all respondents have mental health information. The other possible explanation may be due to its symptoms of schizophrenia are observable in nature or are overt.
Schizophrenia was regarded as severe and but not fatal by the majority of the respondents 278 (68.25). It was also regarded as chronic mental disorders by the majority of the respondents 362 (88.5\%). This is in agreement with a study conducted in Ethiopia [29].

Concerning perceived treatments, 280 (68.5\%) of respondents preferred psychosocial management for schizophrenia. Almost all participants agreed with the treatment outcome as treatable. This may be due to psychology course is included in their curriculum. These results are in harmony with other studies conducted in Ethiopia [29].

Residency is found to be a significant factor that associates with the perceived psychosocial cause of schizophrenia. Respondents with urban residency were found associated with psychosocial and biological perceived cause for schizophrenia. Respondents with rural residency were found associated with supernatural/spiritual perceived cause for schizophrenia disorder. This result is in agreement with the study done in Nigeria regarding the cause of mental illness where urban dwelling was found to be correlated with beliefs in biological and psychosocial causation but rural dwelling was found correlated with beliefs in supernatural causation [29].

The present study found an association between perception about schizophrenia and the source of information. Getting information from mass media and from health professionals was positively associated with the perceived psychosocial cause of schizophrenia. This result is in agreement with results from similar studies conducted in Ethiopia, Hawassa they reported information from mass media and health professionals has good perception towards mental illness [26].

In this study, having another background profession (diploma and degree) showed significant association with perceived biological and psychosocial cause of schizophrenia. On the other hand, not having other background profession (previous training college training) showed significant association with the perceived supernatural cause of schizophrenia. This might be due to better access to information through another profession. This result cannot be compared with other studies because no study was identified which tried to assess the perception of specific mental disorders as well as consider another background profession as a variable.

The result of this study revealed that marital status was significantly associated with perceived psychosocial causes of schizophrenia. Participants who are married were significantly associated with perceiving the psychosocial cause of schizophrenia. This result cannot be compared with other studies because no study was 
Table 4 Bivariate and multivariate analysis of factors associated with perceived cause of schizophrenia by Holy Trinity Theological College students Addis Ababa Ethiopia 2016

\begin{tabular}{|c|c|c|c|c|c|}
\hline \multirow[t]{2}{*}{ Variables } & \multirow[t]{2}{*}{ Categories } & \multicolumn{2}{|c|}{ Biological } & \multirow[t]{2}{*}{ COR $(95 \% \mathrm{Cl})$} & \multirow[t]{2}{*}{ AOR $(95 \% \mathrm{Cl})$} \\
\hline & & No & Yes & & \\
\hline Age & & & & $1.07(0.98,1.049)$ & $1.99(0.96,1.03)$ \\
\hline \multirow[t]{2}{*}{ Marital status } & Single & 191 & 32 & 1.00 & \\
\hline & Marred & 157 & 29 & $1.13(0.63,1.9)$ & \\
\hline \multirow[t]{2}{*}{ Residency } & Urban & 165 & 50 & $5.04(2.53,10.1)$ & $3.33(1.63,6.8)^{* * *}$ \\
\hline & Rural & 183 & 11 & 1.00 & 1.00 \\
\hline \multirow[t]{2}{*}{ Background profession } & Yes & 119 & 48 & $7.1(3.7,13.6)$ & $5.17(2.67,10.23)^{* * *}$ \\
\hline & No & 229 & 13 & 1.00 & 1.00 \\
\hline \multirow[t]{2}{*}{ Family Hx of mental illness } & Yes & 95 & 16 & $0.9(0.5,1.75)$ & \\
\hline & No & 253 & 45 & 1.00 & \\
\hline \multirow[t]{2}{*}{ Previous $\mathrm{Hx}$ of mental illness } & Yes & 11 & 2 & $1.03(0.22,4.80)$ & \\
\hline & No & 337 & 59 & 1.00 & \\
\hline \multirow[t]{9}{*}{ Sources of information } & Social media & & & & \\
\hline & Yes & 268 & 54 & $0.77(0.44,1.34)$ & $0.27(0.73,4.25)$ \\
\hline & No & 80 & 7 & 1.00 & 1.00 \\
\hline & Mass media & & & & \\
\hline & Yes & 202 & 39 & $1.28(0.72,2.25)$ & \\
\hline & No & 146 & 22 & 1.00 & \\
\hline & Health profe & & & & \\
\hline & Yes & 170 & 26 & $2.33(1.08,5.26)$ & \\
\hline & No & 178 & 35 & & \\
\hline \multirow[t]{2}{*}{ Variables } & Categories & \multicolumn{2}{|c|}{ Psychosocial } & COR $(95 \% \mathrm{Cl})$ & AOR $(95 \% \mathrm{Cl})$ \\
\hline & & No & Yes & & \\
\hline Age & & & & $0.9(0.9,0.99)$ & $0.98(0.9,1.03)$ \\
\hline \multirow[t]{2}{*}{ Marital status } & Single & 40 & 183 & 1.00 & 1.00 \\
\hline & Marred & 56 & 130 & $0.50(0.3,0.8)$ & $0.46(0.25,0.86)^{*}$ \\
\hline \multirow[t]{2}{*}{ Residency } & Urban & 38 & 117 & $1.98(1.24 .3 .16)$ & $1.72(1.03,2.86)^{*}$ \\
\hline & Rural & 58 & 136 & 1.00 & 1.00 \\
\hline \multirow[t]{2}{*}{ Background profession } & Yes & 32 & 135 & $1.51(0.93,2.45)$ & $1.43(0.83,2.46)$ \\
\hline & No & 64 & 178 & 1.00 & 1.00 \\
\hline \multirow[t]{2}{*}{ Family $\mathrm{Hx}$ of mental illness } & Yes & 27 & 84 & $0.93(0.56,1.56)$ & \\
\hline & No & 69 & 229 & 1.00 & \\
\hline \multirow[t]{2}{*}{ Previous $\mathrm{Hx}$ of mental illness } & Yes & 4 & 4 & $0.68(0.20,2.26)$ & \\
\hline & No & 92 & 304 & 1.00 & \\
\hline \multirow[t]{9}{*}{ Sources of information } & Mass media & & & & \\
\hline & Yes & 46 & 195 & $1.79(1.33,2.85)$ & $1.99(1.22,3.26)^{* *}$ \\
\hline & No & 50 & 118 & 1.00 & 1.00 \\
\hline & Social media & & & & \\
\hline & Yes & 73 & 249 & $1.26(0.72,2.11)$ & \\
\hline & No & 23 & 64 & 1.00 & \\
\hline & Health profe & & & & \\
\hline & Yes & 35 & 161 & $1.89(1.15,2.95)$ & $1.88(1.15,3.07)^{*}$ \\
\hline & No & 61 & 152 & 1.00 & \\
\hline
\end{tabular}


Table 4 (continued)

\begin{tabular}{|c|c|c|c|c|c|}
\hline \multirow[t]{2}{*}{ Variables } & \multirow[t]{2}{*}{ Categories } & \multicolumn{2}{|c|}{ Supernatural/spiritual } & \multirow[t]{2}{*}{ COR $(95 \% \mathrm{Cl})$} & \multirow[t]{2}{*}{ AOR $(95 \% \mathrm{Cl})$} \\
\hline & & No & Yes & & \\
\hline Age & & & & $1.07(0.9,1.04)$ & $1.07(0.98,1.05)$ \\
\hline \multirow[t]{2}{*}{ Marital status } & Single & 179 & 44 & $1.33(0.83,2.13)$ & $0.78(0.41,1.48)$ \\
\hline & Marred & 140 & 46 & 1.00 & 1.00 \\
\hline \multirow[t]{2}{*}{ Residency } & Urban & 189 & 26 & 1.00 & 1.00 \\
\hline & Rural & 130 & 64 & $3.57(2.15,5.9)$ & $3.17(1.8,5.34)^{* * *}$ \\
\hline \multirow[t]{2}{*}{ Background profession } & Yes & 142 & 25 & 1.00 & 1.00 \\
\hline & No & 177 & 65 & $2.08(1.25,3.47)$ & $1.58(0.9,2.77)$ \\
\hline \multirow[t]{2}{*}{ Family Hx of mental illness } & Yes & 86 & 25 & 1.00 & \\
\hline & No & 233 & 65 & $0.96(0.56,1.62)$ & \\
\hline \multirow[t]{2}{*}{ Previous $\mathrm{Hx}$ of mental illness } & Yes & 11 & 2 & 1.00 & \\
\hline & No & 308 & 88 & $1.57(0.34,7.22)$ & \\
\hline \multirow[t]{9}{*}{ Sources of information } & Mass media & & & & \\
\hline & Yes & 194 & 47 & 1.00 & 1.00 \\
\hline & No & 125 & 43 & $1.420(0.88,2.274)$ & $1.49(0.91,2.45)$ \\
\hline & Social media & & & & \\
\hline & Yes & 253 & 69 & 1.00 & \\
\hline & No & 60 & 21 & $1.16(0.66,2.040)$ & \\
\hline & Health professional & & & & \\
\hline & Yes & 160 & 36 & 1.00 & 1.00 \\
\hline & No & 159 & 54 & $1.59(0.93,2.42)$ & $0.78(0.41,1.48)$ \\
\hline
\end{tabular}

${ }^{*} p<0.05,{ }^{* *} p<0.01,{ }^{* * *} p<0.001$

identified which tried to consider marital status as a variable for each specific mental disorder.

In this study, perceived cause of respondents was not found significantly associated with age, family history of mental illness and previous history of mental illness.

\section{Conclusion}

In the current study, the majority of the participants recognized schizophrenia as a mental illness and a treatable syndrome. Most of the participants thought of psychosocial problems as the cause of schizophrenia. About twothirds of the participant thought schizophrenia as severe but not a fatal illness. Most of the participants (88.5\%) thought schizophrenia as a chronic illness and about $18.8 \%$ reported schizophrenia results in the death. Moreover, $66.7,34.7$, and $7.8 \%$ reported madness, family disintegration and losing a job, respectively, as an outcome. In this study, residency, marital status, and source of information were significantly associated with perceived causes of schizophrenia. Linking mental health service with spiritual care to address community mental health care needs and for early detection as well as referral linkage of mentally ill patients is warranted.

\section{Authors' contributions}

MS conceived the study and was involved in the study design, reviewed the article, analysis, report writing and drafted the manuscript. TA, AM, GA and GA were involved in the study design, analysis and drafted the manuscript. All authors read and approved the final manuscript.

\section{Author details}

${ }^{1}$ Institute of Public Health, College of Medicine and Health Sciences, University of Gondar, Gondar, Ethiopia. ${ }^{2}$ Research and Training Department, Amanuel Mental Specialized Hospital, Addis Ababa, Ethiopia.

\section{Acknowledgements}

The authors acknowledge Amanuel Mental Specialized Hospital, for funding the study. The authors appreciate the respective study institutions and the study participants for their cooperation in providing the necessary information.

\section{Competing interests}

The authors declare that they have no competing interests.

\section{Availability of data and materials}

The data that support the findings of this study are available from the corresponding author on request.

\section{Consent for publication \\ Not applicable.}

Ethics approval and consent to participate Not applicable.

\section{Funding}

The author declares that there is no funding. 


\section{Publisher's Note}

Springer Nature remains neutral with regard to jurisdictional claims in published maps and institutional affiliations.

Received: 12 March 2018 Accepted: 29 September 2018

Published online: 08 October 2018

\section{References}

1. McGrath J, et al. Schizophrenia: a concise overview of incidence, prevalence, and mortality. Epidemiol Rev. 2008;30(1):67-76.

2. Murray C, Lopez A. The global burden of disease. Cambridge: Harvard university press; 1996.

3. Edition F, Association AP. Diagnostic and statistical manual of mental disorders. Washington Google Scholar: American Psychological Association; 1994.

4. Ayano G. Schizophrenia: a concise over view on etiology epidemiology diagnosis and management: review on literature. J Schizophrenia Res. 2016;3(2):2-7.

5. Angermeyer MC, Matschinger $\mathrm{H}$. Causal beliefs and attitudes to people with schizophrenia. Br J Psychiatry. 2005;186(4):331-4

6. Furnham A, Chan E. Lay theories of schizophrenia. Soc Psychiatry Psychiatr Epidemiol. 2004;39(7):543-52.

7. Magliano L, et al. Beliefs about schizophrenia in Italy: a comparative nationwide survey of the general public, mental health professionals, and patients' relatives. Canad J Psychiatry. 2004;49(5):323-31.

8. Nakane Y, et al. Public beliefs about causes and risk factors for mental disorders: a comparison of Japan and Australia. BMC psychiatry. 2005;5(1):33.

9. Lauber C, et al. Lay beliefs about causes of depression. Acta Psychiatr Scand. 2003;108(s418):96-9.

10. Matschinger $\mathrm{H}$, Angermeyer $\mathrm{M}$. Lay beliefs about the causes of mental disorders: a new methodological approach. Soc Psychiatry Psychiatr Epidemiol. 1996;31(6):309-15.

11. McKeon P, Carrick S. Public attitudes to depression: a national survey. Irish J Psychol Med. 1991;8(2):116-21.

12. Priest RG, et al. Lay people's attitudes to treatment of depression: results of opinion poll for defeat depression campaign just before its launch. BMJ. 1996;313(7061):858-9.

13. Link BG, et al. Public conceptions of mental illness: labels, causes, dangerousness, and social distance. Am J Public Health. 1999;89(9):1328-33.

14. Taskin EO, et al. Public attitudes to schizophrenia in rural Turkey. Soc Psychiatry Psychiatr Epidemiol. 2003;38(10):586-92.
15. Shibre T, et al. Perception of stigma among family members of individuals with schizophrenia and major affective disorders in rural Ethiopia. Soc Psychiatry Psychiatr Epidemiol. 2001;36(6):299-303.

16. Saravanan $B$, et al. Perceptions about psychosis and psychiatric services: a qualitative study from Vellore, India. Soc Psychiatry Psychiatr Epidemiol. 2008;43(3):231-8

17. Muga FA, Jenkins R. Public perceptions, explanatory models and service utilisation regarding mental illness and mental health care in Kenya. Soc Psychiatry Psychiatr Epidemiol. 2008:43(6):469.

18. Constantine MG, et al. Exploring indigenous mental health practices: the roles of healers and helpers in promoting well-being in people of color. Couns Values. 2004;48(2):110-25.

19. Kabir M, et al. Perception and beliefs about mental illness among adults in Karfi village, northern Nigeria. BMC Int Health Hum Rights. 2004;4(1):3.

20. Alem A, et al. How are mental disorders seen and where is help sought in a rural Ethiopian community? A key informant study in Butajira, Ethiopia. Acta Psychiatrica Scandinavica. 1999;100(S397):40-7.

21. Giel R, Gezahegn Y, Van Luijk J. Faith-healing and spirit-possession in Ghion, Ethiopia. Soc Sci Med. 1968;2(1):63-79.

22. Lloyd KR, Jacob KS, Patel V, St Louis L, Bhugra D, Mann AH. The development of the Short Explanatory Model Interview (SEMI) and its use among primary-care attenders with common mental disorders. Psychol Med. 1998:28:1231-7.

23. Ayano $\mathrm{G}$, et al. Mental health training for primary health care workers and implication for success of integration of mental health into primary care: evaluation of effect on knowledge, attitude and practices (KAP). Int J Ment Health Syst. 2017;11(1):63.

24. Khandelwal S, Workneh F. Perception of mental illness by medical students. Indian J Psychol Med. 1986;9(1):26-32.

25. Whyte SR. Attitudes towards mental health problems in Tanzania. Acta Psychiatr Scand. 1991:83(S364):59-76.

26. Duko B, Ayano G, Agidew M. Perception, attitude and correlates of alcoholism and epilepsy among residents of Hawassa City, South Ethiopia, cross sectional study. J Psychiatry. 2016;19:359.

27. Agara A, Makanjuola A, Morakinyo O. Management of perceived mental health problems by spiritual. Afr J Psychiatry. 2008;11(2):113-8.

28. Girma E, Tesfaye M. Patterns of treatment seeking behavior for mental illnesses in Southwest Ethiopia: a hospital based study. BMC Psychiatry. 2011;11(1):138

29. Mulatu MS. Perceptions of mental and physical illnesses in northwestern Ethiopia: causes, treatments, and attitudes. J Health Psychol. 1999:4(4):531-49.
Ready to submit your research? Choose BMC and benefit from:

- fast, convenient online submission

- thorough peer review by experienced researchers in your field

- rapid publication on acceptance

- support for research data, including large and complex data types

- gold Open Access which fosters wider collaboration and increased citations

- maximum visibility for your research: over 100M website views per year

At $\mathrm{BMC}$, research is always in progress.

Learn more biomedcentral.com/submissions 